\title{
ベイズ形パターン認識に関する情報論的考察†
}

\author{
片井修・岩井壮介 \\ 京都大学工学部 京都市左京区吉田本町
}

(昭和 47 年 4 月 7 日 受付)

\section{An Information Theoretic Consideration for Bayesian Pattern Recognition}

\author{
Osamu Katai and Sousuke IwaI \\ (Faculty of Engineering, Kyoto University, Kyoto) \\ (Received April 7, 1972)
}

This paper discusses an information theoretic approach for Bayesian dichotomization of patterns.

In the first section, we introduce a new measure which is closely related to the recognition rate of Bayesian pattern recognizer and is easy for practical use. This measure is defined as the correlation between the teacher's response and Bayesian discriminant function.

Further, it is shown that the measure is composed of three non-negative parts well known in information theory and statistics. These parts are analyzed in connection with Bayesian pattern recognition.

In the second section, the relation between the recognition rate and the measure is discussed by the aid of central limit theorem. This relation assures the usefulness of the measure in the synthesis of pattern recognizer and the quantization of patterns.

Experimental computer simulation ascertains the above discussions and results.

\section{1. 緒}

言

ベイズ形パターン認識機構の構造は, 入力として加 えられるパターン空間の確率構造によって一義的に決 定され，ベイズ決定の意味飞执いて最適の形を有する. したがって識別機構の性能，すなわち正解率ない乙誤 り確率は識別しょうとするパターン集合間の確率構造 的な分離の度合, パターン空間座標系の選び方などに よって大きく影響される. 正解率の把握は, 正解率乞 のものの解析的表現のむずかしさ，確率構造をこの目 的汶して定量的に表わす尺度として十分なるのが見 当たらないなどの理由によって十分には行なわれてい ない，パターンクラスの族 $R=\{R, \bar{R}\}$ に属するパタ ーンクラスがそれぞれ条件確率 $P(\boldsymbol{X} \mid R), P(\boldsymbol{X} \mid \bar{R})$ で 規定されているとき，両パターンクラスの分離度を表 $\dagger$ 第 14 回自動制御連合講演会で発表 (昭 46.11)
わす尺度として，

Bhattacharyya distance $B=-\ln$

$$
\int \sqrt{P(\boldsymbol{X} \mid R) \cdot P(\boldsymbol{X} \mid \bar{R})} d \boldsymbol{X}
$$

divergence $J=\int\{P(\boldsymbol{X} \mid R)-P(\boldsymbol{X} \mid \bar{R})\} \ln \frac{P(\boldsymbol{X} \mid R)}{P(\boldsymbol{X} \mid \bar{R})} d \boldsymbol{X}$

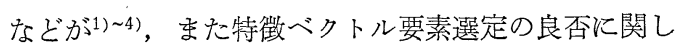
ては，各ベクトル要素を通信路と見なすことにより， その情報伝達の有効さを示す尺度として知られている シャノンの相互情報量を用いることができるが5)，こ れらの尺度はそれぞれ，確率構造のある一面を反映す るものであって, 正解率, 誤り確率といったもの之直 接結びっくものではない(6),7).

本論文はベイズ形パターン認識機構に执いて, パタ ーンベクトル要素数が非常に多く, かつ要素間独立 
性が成り立つとの仮定のもとに, 中心極限定理の適用 から正解率を導出し，これと対象とするパターン集合 の有する総合的な識別の尺度として新しく定義した平 均情報強度との関係, 従来より提唱されている情報尺 度, 分離度との関連について考察したるのである。

\section{2. 平均情報強度の定義とその構造}

$n$ 次元パターンベクトル $\boldsymbol{X}=\left(X_{1}, X_{2}, \cdots, X_{n}\right)$ は離 散的值をとり, パターンクラスの族 $\mathscr{R}=\{R, \bar{R}\}$ のい ずれかの要素クラスに属するものとし，それぞれに対 する確率分布 $P(\boldsymbol{X} \mid R), P(\boldsymbol{X} \mid \bar{R})$, 各クラスの生起確 率を $P(R), P(\bar{R})$ とする. いま識別関数を $f(\boldsymbol{X})$ と するクラス $R$ に対する識別システムを考える場合， 入 カパターン群 $\boldsymbol{X}$ に対する識別のための情報量の尺度と して, $f(\boldsymbol{X})$ の值と teacher の応答 $d^{*}$ の相関をとる ことが考えられる.すなわち，

$$
\begin{gathered}
S_{\mathscr{R}}(\boldsymbol{X}) \rightleftharpoons E\left[d^{*} \cdot f(\boldsymbol{X})\right] \\
d^{*}=\left\{\begin{array}{cl}
1 & (\boldsymbol{X} \in R) \\
-1 & (\boldsymbol{X} \in \bar{R})
\end{array}\right.
\end{gathered}
$$

いま識別機構をべイズ形に限定し，よく行なわれる ように識別関数 $f(\boldsymbol{X})$ として,

$$
f(\boldsymbol{X})=\ln \frac{P(R \mid \boldsymbol{X})}{P(\bar{R} \mid \boldsymbol{X})}
$$

を選ぶものとする．この場合，上記情報量の尺度 $S_{\mathscr{R}}$ は,

$$
\begin{aligned}
S_{\mathscr{R}}(\boldsymbol{X})= & P(R) E_{R}\left[\ln \frac{P(R \mid \boldsymbol{X})}{P(\bar{R} \mid \boldsymbol{X})}\right] \\
& +P(\bar{R}) E_{\bar{R}}\left[\ln \frac{P(\bar{R} \mid \boldsymbol{X})}{P(R \mid \boldsymbol{X})}\right]
\end{aligned}
$$

と表わすことができる。ここに $E_{R}, E_{\bar{R}}$ はそれぞれ $R$, $\bar{R}$ から発生されたパターンについて期待值をとること を意味する. パターンベクトル $\boldsymbol{X}$ の要素 $X_{i}(i=1 \sim n)$ が 1〜 の の離散的な值をとり，かつ要素間が独立であ る場合，上式は，

$$
\begin{gathered}
S_{\mathscr{R}}(\boldsymbol{X})=\sum_{i=1}^{n} S_{\mathscr{R}}\left(X_{i}\right)+J(P(R), P(\bar{R})) \\
J(P(R), P(\bar{R})) \rightleftharpoons P(R) \ln \frac{P(R)}{P(\bar{R})}+P(\bar{R}) \ln \frac{P(\bar{R})}{P(R)} \\
S_{\mathscr{R}}\left(X_{i}\right) \rightleftharpoons \sum_{X_{i}=1}^{k} P\left(X_{i}, R\right) \ln \frac{P\left(X_{i} \mid R\right)}{P\left(X_{i} \mid \bar{R}\right)} \\
+\sum_{X_{i}=1}^{k} P\left(X_{i}, \bar{R}\right) \ln \frac{P\left(X_{i} \mid \bar{R}\right)}{P\left(X_{i} \mid R\right)}
\end{gathered}
$$

と書くことができる. (7) 式第 2 項 $J(P(R), P(\bar{R}))$ は 2 つのパターンクラスの出現確率 $P(R), P(\bar{R})$ の間 の分離の度合を表わす Hájek の divergence に相当 する量であり, a priori に与えられる情報の量を表わ
するのと解釈される. $S_{\mathbb{R}}\left(X_{i}\right)$ はパターンベクトル要 素 $X_{i}$ の有する識別のための情報尺度と考学られるす のであって，これをべクトル要素 $X_{i}$ の有する平均情 報強度と呼ぶことにする。

$S_{\mathscr{R}}\left(X_{i}\right)$ は統計学あるいは情報理論で良く知られた 3 つの情報尺度，すなわち Bhattacharyya distance, シャノンの相互情報量特よび Kullback-Leibler number を用いてつぎのように表現することができる（付 録 1).

$$
\begin{gathered}
S_{\mathscr{R}}\left(X_{i}\right)=2\left\{B\left(P\left(X_{i} \mid R\right), P\left(X_{i} \mid \bar{R}\right)\right)+R\left(X_{i}, \mathscr{R}\right)\right. \\
\left.+I\left(P\left(X_{i}\right): P^{*}\left(X_{i}\right)\right)\right\} \\
R\left(X_{i}, \mathscr{R}\right)=-\sum_{X_{i}=1}^{k} P\left(X_{i}\right) \ln P\left(X_{i}\right) \\
\quad+\sum_{X_{i}=1}^{k} P\left(X_{i}, R\right) \ln P\left(X_{i} \mid R\right) \\
\quad+\sum_{X_{i}=1}^{k} P\left(X_{i}, \bar{R}\right) \ln P\left(X_{i} \mid \bar{R}\right) \\
B\left(P\left(X_{i} \mid R\right), P\left(X_{i} \mid \bar{R}\right)\right)=-\ln \rho_{i} \\
\rho_{i}=\sum_{X_{i}=1}^{k} \sqrt{P\left(X_{i} \mid R\right) P\left(X_{i} \mid \bar{R}\right)} \\
I\left(P\left(X_{i}\right): P^{*}\left(X_{i}\right)\right)=\sum_{\sum_{i}=1}^{k} P\left(X_{i}\right) \ln \frac{P\left(X_{i}\right)}{P^{*}\left(X_{i}\right)} \\
P\left(X_{i}\right)=P(R) P\left(X_{i} \mid R\right)+P(\bar{R}) P\left(X_{i} \mid \bar{R}\right) \\
P^{*}\left(X_{i}\right)=\frac{\sqrt{P\left(X_{i} \mid R\right) P\left(X_{i} \mid \bar{R}\right)}}{\rho_{i}}
\end{gathered}
$$

以下，これら 3 つの成分のパターン認識に関して有 する意味を考察する。

第 1 項 Bhattacharyya distance $B$ は両パターンク ラスの事前確率 $P(R), P(\bar{R})$ には無関係に決定され

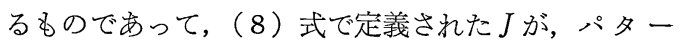
ンクラスの特幑には無関係に事前確率の片よりによる 識別のし易さの評価量であったのに対し, 各要素 $X_{i}$

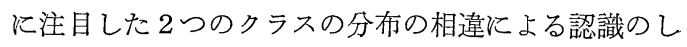
易さの尺度を与えるものと考劣るこがでさる. Bhattacharyya distance に関しては,つぎのような幾何 学的説明が与えられている4). 観測要素 $X_{i}$ の実現值 1〜kに関する条件確率に対し，光れぞれ次のような $k$ 次元ベクトル,

$\left.\begin{array}{l}\boldsymbol{P}_{1}^{i}=\left(\sqrt{P\left(X_{i}=1 \mid R\right)}, \sqrt{P\left(X_{i}=2 \mid R\right)}, \cdots, \sqrt{\left.P\left(X_{i}=k \mid R\right)\right)}\right. \\ \boldsymbol{P}_{2}{ }^{i}=\left(\sqrt{P\left(X_{i}=1 \mid \bar{R}\right)}, \sqrt{P\left(X_{i}=2 \mid \bar{R}\right)}, \cdots, \sqrt{\left.P\left(X_{i}=k \mid \bar{R}\right)\right)}\right.\end{array}\right\}$

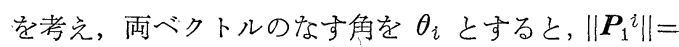
$\left\|\boldsymbol{P}_{2}{ }^{i}\right\|=1$ であることから，

$$
\rho_{i}=\left(\boldsymbol{P}_{1}^{i}, \boldsymbol{P}_{2}^{i}\right)=\cos \theta_{i}
$$

すなおち, Bhattacharyya distance $B$ と両分布の分 離の度合の幾何学的表現である $\theta_{i}$ との間には,

$$
B\left(P\left(X_{i} \mid R\right), P\left(X_{i} \mid \bar{R}\right)\right)=-\ln \cos \theta_{i} \geq 0
$$


なる関係が成立する。明らかに, $0 \leq \theta_{i} \leq \pi / 2$ であり, $\theta_{i}=0$ すなわち $X_{i}$ を観測しても識別に関してなんら 情報の得られない場合には $B=0, \theta_{i}=\pi / 2$ すなわち $X_{i}$ のみを観測することによりパターンの属するクラ スが完全に決定される場合には $B=\infty$ となる.

以上のように (7) 式の第 2 項 $J$ および平均情報強 度 $S_{\mathscr{R}}\left(X_{i}\right) \cdot$ 第 1 項 $B$ はそそれぞれパターンクラスの 事前確率怙よび各パターンクラスを特街づける条件確 率自体の分離の度合を表わするのであって, これらの 值が直接認識のし易さに関係することほ明らかである。 しかしながら, 認識能率を左右するものとしては上記 事前確率, 条件確率それぞれの分離度のほか，両者の 間の関連の仕方がとうぜん考兄られる。(10) 式の表 現に括ける平均情報強度の第 2 , 第 3 項が, 関連のし かたの良否を表わするのと考えられる.

第 2 項 $R\left(X_{i}, \mathscr{R}\right)$ はシャノンの相互情報量であり, 次式のようにェントロピーの差で与兄られる.

$$
\begin{aligned}
R\left(X_{i}, \mathscr{R}\right)= & H(\mathscr{R})-H\left(\mathscr{R} \mid X_{i}\right) \\
H(\mathscr{R})=- & P(R) \ln P(R)-P(\bar{R}) \ln P(\bar{R}) \\
H\left(\mathscr{R} \mid X_{i}\right)= & -\sum_{X_{i}=1}^{k} P\left(X_{i}, R\right) \ln P\left(R \mid X_{i}\right) \\
& \quad-\sum_{X_{i}=1}^{k} P\left(X_{i}, \bar{R}\right) \ln P\left(\bar{R} \mid X_{i}\right)
\end{aligned}
$$

いま，パターンベクトル要素 $X_{1} \sim X_{n}$ を $n$ 個の信 号伝送路受信端と考光, 入力端に対して与兄られた事 前確率に従う $m$ 個のパターンクラス $R, \bar{R}$ の提示が 行なわれたとする. 入力系列の数としては $m \gg 1$ の場 合には，よく知られているように $N=\exp [m \cdot H(R)]$ 個のものが等確率で生起すると考光ることができる8). $N$ の值は,

$$
H(R) \geq H_{\max }-J(P(R), P(\bar{R}))
$$

が成立することから, 事前確率の分離の度合 $J$ が小さ いほど大きくなる（20) 式第 2 項 $H\left(\mathscr{R} \mid X_{i}\right)$ は受信 端 $X_{i}$ 亿怙ける曖昧度を表わして沏り, 入力パターン クラス系列の $N_{i}=\exp \left[m \cdot H\left(R \mid X_{i}\right)\right]$ 個のいずれも が等確率でこの観測值系列となりらることを意味する。 $N_{i}$ の值は,

$$
\begin{aligned}
& H\left(R \mid X_{i}\right) \leq 2 C \sqrt{P(R) P(\bar{R})} \\
& \quad \exp \left[-B\left(P\left(X_{i} \mid R\right), P\left(X_{i} \mid \bar{R}\right)\right)\right] \\
& C=\max _{0 \leq x \leq 1}[\{-x \ln x-(1-x) \ln (1-x)\} / \sqrt{x}] \quad(22)
\end{aligned}
$$

なる関係によってその上限が与えられ ${ }^{9)}$, 観測要素 $X_{i}$ 飞特ける 2 つのハターンクラスの特徽差 $B$ に関係し， 伝送路 $i=1 \sim n$ によってその值を異にする. (20) 式 より， $N, N_{i}$ および $R\left(X_{i}, \mathscr{R}\right)$ の間には次式が成立 する。

$$
\frac{N_{i}}{N}=\exp \left[-m \cdot R\left(X_{i}, \mathscr{R}\right)\right]
$$

すなわち, $B$ が第 $i$ 番目の要素 $X_{i}$ 自体の有効性に 関連した尺度であるのに対し， $R$ は a priori な情報 （事前確率を知ることによる情報一 $J$ で評価された） を得た後に, 実際の確率過程による情報伝達（第 $i$ 番 目の要素を通しての）の平均的有効性の尺度と考兄ら れる.

第 3 の成分 $I\left(P\left(X_{i}\right): P^{*}\left(X_{i}\right)\right)$ は次のように書き かえることができる。

$$
\begin{gathered}
I\left(P\left(X_{i}\right): P^{*}\left(X_{i}\right)\right)=\sum_{j=1}^{k} P\left(X_{i}=j\right) \cdot \ln L_{j}^{i} \\
L_{j}^{i}=\frac{P\left(X_{j}=j\right)}{P^{*}\left(X_{i}=j\right)}=\rho_{i} \sqrt{P(R) P(\bar{R})}\left(\sqrt{T_{j}^{i}}+\frac{1}{\sqrt{T_{j}^{i}}}\right) \\
T_{j}^{i}=\frac{P\left(R \mid X_{i}=j\right)}{P\left(\bar{R} \mid X_{i}=j\right)} \quad j=1 \sim k
\end{gathered}
$$

すなわち， $T_{j}^{i}$ は $X_{i}$ の実現值 $j$ を得たもとでの事後 確率の比であり，したがってその対数值は実現值 $j$ の もつ情報の量と考学ることができる。

$I\left(P\left(X_{i}\right): P^{*}\left(X_{i}\right)\right)$ は $L_{j}^{i}=1(j=1 \sim k)$ のとき最 小值 0 をとる. これは事前確率の比 $T_{j}^{i}$ が $j$ によっ $\tau$

$$
\bar{T}^{i}=\frac{1+\sqrt{1-4 \rho_{i}{ }^{2} \cdot P(R) P(\bar{R})}}{2 \rho_{i} \sqrt{P(R) P(\bar{R})}}
$$

または $1 / \bar{T}^{i}$ のいずれかの值をとることに対応する。 したがって，情報量の絶詨值 $\left|\ln T_{j}^{i}\right|$ が各実現值につ いて不均一になるほど第 3 の成分 $I$ は大きくなる.

すなわち, 第 2 の成分, 相互情報量 $R$ が, 観測要素 $X_{i}$ の情報伝達の平均的有効性を表わすものであるの に対し, 第 3 の成分 $I$ は, 要素 $X_{i}$ に括ける実現值の 現われ方がクラス識別に詨しいかに効果的であるかの 尺度を与えるものと解釈することができる.

以上, 新しく定義した平均情報強度 $S_{\mathscr{R}}\left(X_{i}\right)$ が, 従来より用いられている 3 つの情報尺度の和として表 わされることを示し，それぞれについてパターン識別 の立場からの解釈を与えたが，これらの尺度はそれぞ れ情報量の 1 側面を表わすものであり, 平均情報強度 の識別情報量の尺度としての有効性は正解率の観点か ら吟味する必要がある。

\section{3. 正解率の近似的評価と平均情報強度との 関係}

緒言に扣いて述べたよらに，正解率の解析的表現は 一般に困難である．ここではある種の仮定のもとに， ベイズ形認識機構の正解率を中心極限定理を用いて近 似することを考える。 


\section{1 正解率の近似的計算}

パターンクラス $R, \bar{R}$ に関する第 1 種過誤の意味で の正解率をそれぞれ $P_{R}, P_{\bar{R}}$ (これらを片側正解率 と 呼ぶことにする）で表わす。

$$
\begin{aligned}
& P_{R}=\text { Prob. }(\boldsymbol{X} \rightarrow \text { decision } R \mid R), \\
& P_{\bar{R}}=\operatorname{Prob} .(\boldsymbol{X} \rightarrow \text { decision } \bar{R} \mid \bar{R})
\end{aligned}
$$

正解率 $P_{C}$ は上記の量を用いて次のように表わされる.

$$
P_{C}=P(R) \cdot P_{R}+P(\bar{R}) \cdot P_{\bar{R}}
$$

いま, パターンベクトル要素間の確率的独立性（厳 密には捈の扮ののパターンクラスに拈いて確率的に独 立）歀よび要素数 $n$ が十分大であるものと仮定すると， $P_{R}$ は近似的に次のように表わされる（付録 2).

$$
\left.\begin{array}{l}
P_{R} \cong \frac{1}{2}+\frac{1}{2} \Phi\left(\frac{\sum_{i=1}^{n} I_{R}\left(X_{i}\right)+\ln P(R)-\ln P(\bar{R})}{\sqrt{2 \sum_{i=1}^{n} V_{R}\left(X_{i}\right)}}\right) \\
\Phi(x)=\frac{1}{\sqrt{\pi}} \int_{-x}^{x} \exp \left(-t^{2}\right) d t
\end{array}\right\}
$$

ここに, $I_{R}: V_{R}$ は尤度比の対数 $\ln P\left(X_{i} \mid R\right) / P\left(X_{i} \mid \bar{R}\right)$ を確率変数（ $X_{i}$ を $R$ のもとでの確率変数として）と 考劣たときの期待值, 分散を表わす.

$$
\begin{gathered}
I_{R}\left(X_{i}\right) \rightleftharpoons \sum_{i=1}^{k} P\left(X_{i} \mid R\right) \ln \frac{P\left(X_{i} \mid R\right)}{P\left(X_{i} \mid \bar{R}\right)} \\
V_{R}\left(X_{i}\right) \rightleftharpoons \sum_{X_{i}=1}^{k} P\left(X_{i} \mid R\right)\left\{\ln \frac{P\left(X_{i} \mid R\right)}{P\left(X_{i} \mid \bar{R}\right)}\right\}^{2}-I_{R}{ }^{2}\left(X_{i}\right)
\end{gathered}
$$

$I_{R}, I_{\bar{R}}$ を用いると，前節で定義した平均情報強度は 次式で与えられる.

$$
S_{R}\left(X_{i}\right)=P(R) \cdot I_{R}\left(X_{i}\right)+P(\bar{R}) \cdot I_{\bar{R}}\left(X_{i}\right)
$$

定義からも明らかなように, 平均情報強度は情報の平 均值のみに関連し，ばらつきには無関係な量である。

\section{$3 \cdot 2$ 平均情報強度と正解率との関係}

要素 $X_{i}$ を観測から落すことによる片側正解率 $P_{R}$ $\left(P_{\bar{R}}\right.$ についても同様) の減少量 $\Delta_{i} P_{R}$ は次のよ 5 に

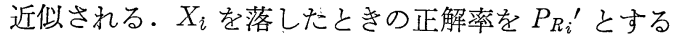
と(付録 3 ),

$$
\begin{aligned}
& \Delta_{i} P_{R} \equiv P_{R}-P_{R_{i}}{ }^{\prime} \\
& \cong \frac{1}{\sqrt{2 \pi(n-1) \bar{V}_{R}^{i}}} \exp \\
& \quad \times\left\{-\frac{1}{2}\left(\frac{(n-1) \bar{I}_{R}^{i}+\ln P(R)-\ln P(\bar{R})}{\sqrt{(n-1) \bar{V}_{R}^{i}}}\right)^{2}\right\} \cdot g_{R}\left(X_{i}\right)
\end{aligned}
$$

$$
g_{R}\left(X_{i}\right) \equiv I_{R}\left(X_{i}\right)-\frac{1}{2} \frac{\bar{I}_{R}^{i}}{\bar{V}_{R}^{i}} V_{R}\left(X_{i}\right)
$$

* $P \bar{R}, I \bar{R}\left(X_{i}\right)$ および $V \bar{R}\left(X_{i}\right)$ は (30), (31) および (32) 式において， $R$ と育を交換したもので表わされる.

$$
\bar{I}_{R}^{i}=\frac{1}{n-1} \sum_{j \neq i} I_{R}\left(X_{j}\right), \quad \bar{V}_{R}^{i}=\frac{1}{n-1} \sum_{j \neq i} V_{R}\left(X_{j}\right)
$$

(34)式に括ける $g_{R}\left(X_{i}\right)$ 以外の項はすべての $i$ につ いてほぼ一定であり, 各要素の正解率への相対的寄与 の度合は $g_{R}\left(X_{i}\right)$ を用いて測ることができる. $g_{R}\left(X_{i}\right)$ は, 片側正解率 $P_{R}$ に関して $X_{i}$ のもつ情報の価值を 表わすものと考光られ, 先述の尤度比の対数 $\ln P$ $\left(X_{i} \mid R\right) / P\left(X_{i} \mid \bar{R}\right)$ の平均值 $I_{R}$ 以外に, そのばらつき $V_{R}$ が負の影響を与兄ていることがわかる. (35) 式 から,

$$
g_{R}\left(X_{i}\right) \gtrless 0 \Leftrightarrow \frac{I_{R}\left(X_{i}\right)}{V_{R}\left(X_{i}\right)} \gtrless \frac{1}{2} \frac{\bar{I}_{R^{i}}}{\overline{\bar{V}}_{R^{i}}}
$$

上式における $I_{R} / V_{R}, \bar{I}_{R}^{i} / \bar{V}_{R}^{i}$ はそれぞれ $X_{i}$ 牡よび $X_{i}$ 以外の要素から得られる情報の精度を表わし, 両 者の相対的関係により $g_{R}\left(X_{i}\right)$ は負の值をもとり らる。

両パターンクラス $R, \bar{R}$ について $X_{i}$ のもつ情報の 価值を, $g_{R}\left(X_{i}\right), g_{\bar{R}}\left(X_{i}\right)$ の事前確率による重みつき 平均 $g_{R}\left(X_{i}\right)$ で考学るものとすると, (33) 式から,

$$
\begin{aligned}
g_{\mathscr{R}}\left(X_{i}\right) & \equiv P(R) \cdot g_{R}\left(X_{i}\right)+P(\bar{R}) \cdot g \bar{R}\left(X_{i}\right) \\
& =S_{\mathscr{R}}\left(X_{i}\right)-K_{\mathscr{R}}\left(X_{i}\right) \\
K_{\mathscr{R}}\left(X_{i}\right) \rightleftharpoons & \frac{1}{2}\left\{P(R) \frac{\bar{I}_{R}^{i}}{\bar{V}_{R}^{i}} V_{R}\left(X_{i}\right)+P(\bar{R}) \frac{\bar{I}_{\bar{R}}{ }^{i}}{\bar{V}_{\bar{R}}^{i}} V_{\bar{R}}\left(X_{i}\right)\right\}
\end{aligned}
$$

すなわち要素 $X_{i}$ の有する識別のための情報価值 $g_{\mathscr{R}}$ $\left(X_{i}\right)$ は, さきに定義した平均情報強度 $S_{\mathscr{R}}\left(X_{i}\right)$ 以外 に $X_{i}$ のもつ情報のばらつきに関連した項 $K_{\mathscr{R}}\left(X_{i}\right)$ が負の効果として働き, その効果の大小は識別機構を 構成する他の要素全体の情報の精度 (信頼度) $\overline{\bar{I}}_{R}{ }^{i} / \bar{V}_{R}{ }^{i}$, $\bar{I}_{\bar{R}}^{i} / \bar{V} \bar{R}^{i}$ により決定される. すなわち, 他の観測要素 のもつ情報の精度が高い場合, 負の効果を表わす項 $K_{\mathscr{R}}\left(X_{i}\right)$ も大きい. その意味から $K_{\mathbb{R}}\left(X_{i}\right)$ は， $X_{i}$ の正解率に及ぼす寄与の度合に関して， $X_{i}$ 自身の有 する情報量 $S_{\mathscr{R}}\left(X_{i}\right)$ のうち, 他の観測要素からの情 報により相殺される情報の量を表わするのと解釈され る.

以上のように, 正解率の観点から考えた情 報 価値 $g_{\mathscr{R}}\left(X_{i}\right)$ と平均情報強度 $S_{\mathbb{R}}\left(X_{i}\right)$ の間には直接の関 係は成立しない。しかし，次に述べるような 2 つの場 合には両者の間に近似的に線形な関係が成立する.

$3 \cdot 3$ 要素間に類似性のある場合, および両パター ンクラスが類似している場合における情 報 価 値と平均情報強度との関係

以下に示す 2 つ場合に和いては近似的に,

$$
g_{\mathscr{R}}\left(X_{i}\right) \cong \frac{1}{2} S_{\mathscr{R}}\left(X_{i}\right)
$$


の関係が成立し, $S_{\mathscr{R}}\left(X_{i}\right)$ が $X_{i}$ の有する識別情報量 の有効な尺度であることがわかる。

$\left.1^{\circ}\right)$ すべてのパターンベクトル要素の確率構造が 類似している場合 すなわち， $I_{R}\left(X_{i}\right), V_{R}\left(X_{i}\right)$ ， $\bar{I}_{\bar{R}}\left(X_{i}\right), V_{\bar{R}}\left(X_{i}\right)$ がすべての $i$ 亿ついてほぼ一定の場 合, (39) 式から,

$$
\begin{aligned}
K_{\mathcal{R}}\left(X_{i}\right) \cong & \frac{1}{2}\left\{P(R) \frac{(n-1) I_{R}\left(X_{i}\right)}{(n-1) V_{R}\left(X_{i}\right)}\right. \\
& \left.+P(\bar{R}) \frac{(n-1) I_{\bar{R}}\left(X_{i}\right)}{(n-1) V_{\bar{R}}\left(X_{i}\right)}\right\} \\
= & \frac{1}{2}\left\{P(R) I_{R}\left(X_{i}\right)+P(\bar{R}) I_{\bar{R}}\left(X_{i}\right)\right\}=\frac{1}{2} S_{\mathscr{R}}\left(X_{i}\right)
\end{aligned}
$$

すなわち，すべての観測要素が同じような情報を提供 する場合, その情報の半分が他の観測要素からの情報 により相殺され，したがって $X_{i}$ の有する識別情報価 值 $g_{\mathscr{R}}\left(X_{i}\right)$ と平均情報強度 $S_{\mathscr{R}}\left(X_{i}\right)$ の間注 (40) 式が成立する。

しかし， $1^{\circ}$ ) の場合は実際的には trivial な場合で あり，実際上興味あるのはつぎの場合である：

$2^{\circ}$ ) 両パターンクラスが類似している場合す なわち、

$$
P\left(X_{i} \mid R\right) \simeq P\left(X_{i} \mid \bar{R}\right) \quad i=1 \sim n
$$

あるいは厳密には,
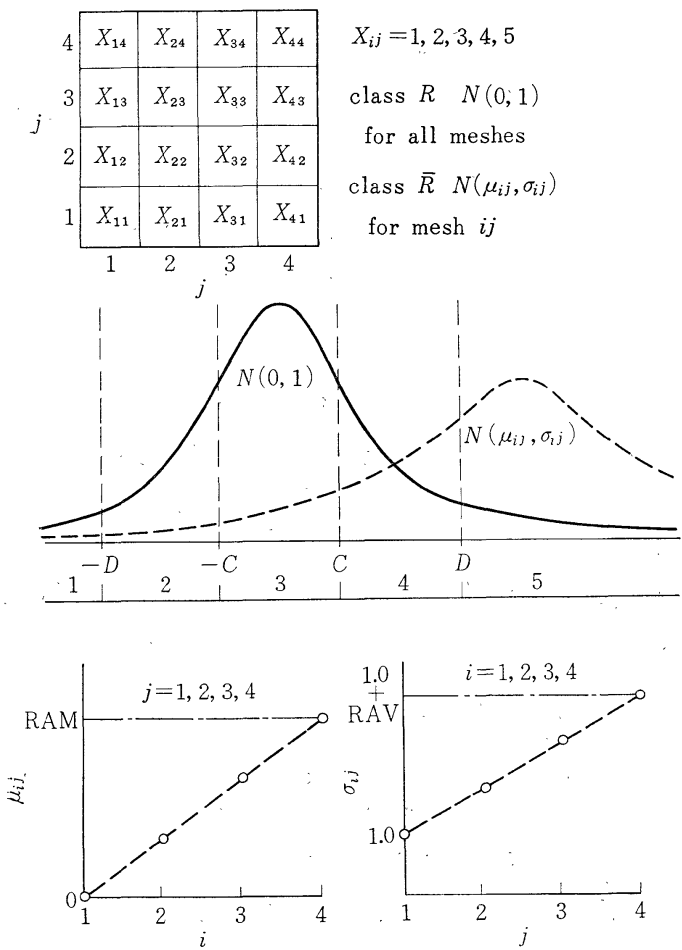

Fig. 1 Input pattern models for computer simulation

$$
\left|P\left(X_{i} \mid \bar{R}\right)-P\left(X_{i} \mid R\right)\right| \ll P\left(X_{i} \mid R\right) \quad i=1 \sim n
$$
なる場合には, 2 つのハターンクラスの確率構造が類 似であって識別がむずかしくなる。この場合， $I_{R}, V_{R}$ はそれぞれつぎのように近似される（付録 4).

$$
\begin{aligned}
& I_{R}\left(X_{i}\right) \cong \frac{1}{2} \sum_{X_{i}=1}^{k} \frac{\left(P\left(X_{i} \mid R\right)-P\left(X_{i} \mid \bar{R}\right)\right)^{2}}{P\left(X_{i} \mid R\right)}, \\
& V_{R}\left(X_{i}\right) \cong \sum_{X_{i}}^{k} \frac{\left(P\left(X_{i} \mid R\right)-P\left(X_{i} \mid \bar{R}\right)\right)^{2}}{P\left(X_{i} \mid R\right)} \\
& \text { 上式より, } i=1 \sim n \text { につて, } \\
& V_{R}\left(X_{i}\right) \cong 2 I_{R}\left(X_{i}\right), \quad V_{\bar{R}}\left(X_{i}\right) \cong 2 I_{\bar{R}}\left(X_{i}\right)
\end{aligned}
$$

が成立する。したがって，(36)，(39）式から，

$$
\begin{aligned}
K_{\mathscr{R}}\left(X_{i}\right) & \cong \frac{1}{2}\left\{P(R) I_{R}\left(X_{i}\right)+P(\bar{R}) I_{\bar{R}}\left(X_{i}\right)\right\} \\
\ldots & =\frac{1}{2} S_{\mathscr{R}}\left(X_{i}\right) .
\end{aligned}
$$

\section{4. 計算機シミュレーションによる検討}

前章では正解率に及ぼす各パターンベクトル要素の 効果が新しく定義した平均情報強度によって，いくつ かの近似のもとに評価できることを示した。

ここでは，これら近似式の妥当性，ならびに平均情 報強度とそ机を構成する 3 つの成分の性質を，モデル を用いた計算機シミュレーションにより検討する。

実験に用いたモデルパターンは，Fig. 1 に示すよ ら飞 $4 \times 4$ の計 16 要素から成り, 各要素 $X_{i j}$ は, クラス $R$ 飞招いてはすべての $i, j$ にいて一様に平 均 0 , 分散 1 の正規乱数を $-D,-C, C, D$ の 4 点で 量子化した，1〜5 の值をとる確率変数とし，クラス $\bar{R}$ 亿怙いては平均 $\mu_{i j}$, 分散 $\sigma_{i j}$ の正規乱数を同様の 手法で量子化したものを確率变数としてとる．また， $\mu_{i j}$ 拈よび $\sigma_{i j}$ の值はそれぞれ，

$$
\mu_{i j}=\frac{\mathrm{RAM}}{3}(i-1), \sigma_{i j}=\frac{\mathrm{RAV}}{3}(j-1)+1
$$

で与えられるものとする。すなおち，パターンを構成 する 16 要素は確率特性がすべて相異なるるのであり, また RAM, RAV の值によってパターンクラス $R, \bar{R}$ の相違の度合を規定することができる、計算機シミュ レーションはクラス $R, \bar{R}$ 飞属するパターン各 3000 個, $C=0.3, D=0.9$ の場合について行なった.

$\left.1^{\circ}\right)$ 中心極限定理の仮定と正解率理論計算式 (30) の妥当性の検討 正解率の近似式 (30) はパターン ベクトル要素の独立性の仮定, ならび要素数 $n$ が十 分大であるとの前提のもとに中心極限定理を用いて導 出したものである.いっぽう, 本解析で用いた識別情報 価值 $g_{\mathscr{R}}\left(X_{i j}\right)$ は要素 $X_{i j}$ の有する正解率の增分を表 わすものである関係上，あまり要素数を多くすると $g_{\mathscr{R}}\left(X_{i j}\right)$ の值が小さくなり信頼度（実験值の）が悪 
Table 1 Comparison of theoretical and experimental recognition rate

\begin{tabular}{l||c|c}
\hline \multicolumn{1}{l||}{$\begin{array}{l}\text { RAM } \\
(=\text { RAV })\end{array}$} & \multicolumn{2}{c}{ true recognition rate $P_{C}[\%]$} \\
\hline 0.5 & theoretical & experimental \\
\hline 1.0 & 76.6 & 76.8 \\
1.5 & 89.5 & 89.1 \\
2.0 & 95.3 & 94.9 \\
& 98.0 & 97.3 \\
\hline
\end{tabular}

くなる、したがって，本シミュレーションではパター ン要素数 $n$ としては比較的少ない $4 \times 4=16$ を用いた が，（30）式汇るる理論計算結果とシミュレーション 実験結果とは Table 1 亿示すように $0.5 \%$ 程度の差 が認められるだけで中心極限定理の仮定，したがって (30) 式が十分成立していることがわかる.

$2^{\circ}$ ） 正解率減少量（34）式の精度に対する検討 つぎに要素 $X_{i j}$ の正解率に寄与する度合を表わす (34) 式の妥当性について検討する.モデルパターンに 括いて特徵的な 3 つの要素 $X_{41}\left(P\left(X_{41} \mid \bar{R}\right)=N(\right.$ RAM, 1)), $X_{14}(N(1, \mathrm{RAV})), X_{44}(N(\mathrm{RAM}, \mathrm{RAV}))$ 飞つい て，(34）式による理論結果とシミュレーション結果 とをパーセントで示したのが Fig. 2 である. 両者の 間にはかなりの差が認められるが、だいたいの傾向は

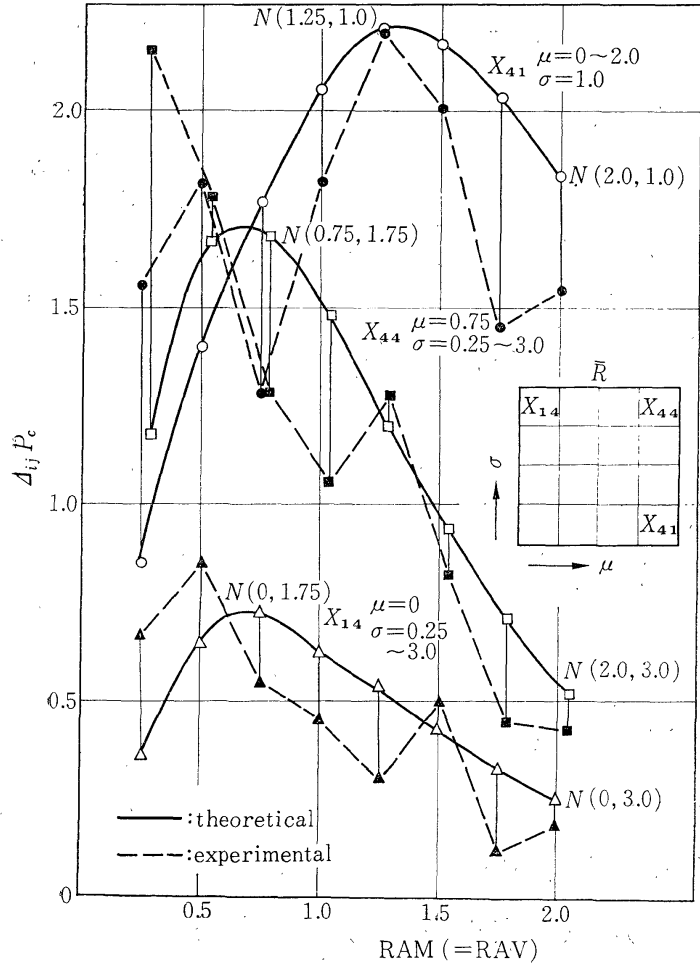

Fig. 2 Comparison of theoretical and experimental decrease of recognition rate
一致している．提示パターン数を種々変えて検討した 結果，この偏差は主に提示パターン数の不足に起因す るものと思われる。

$3^{\circ}$ ） 情報価值と平均情報強度の間の対応関係に対 する検討 $\left.3 \cdot 3,2^{\circ}\right)$ で述べた両クラス $R, \bar{R}$ の相 違の少ない場合（RAM，RAV が小なることに対応）， (40) 式がどの程度成立するかを Fig. 3 に示す.

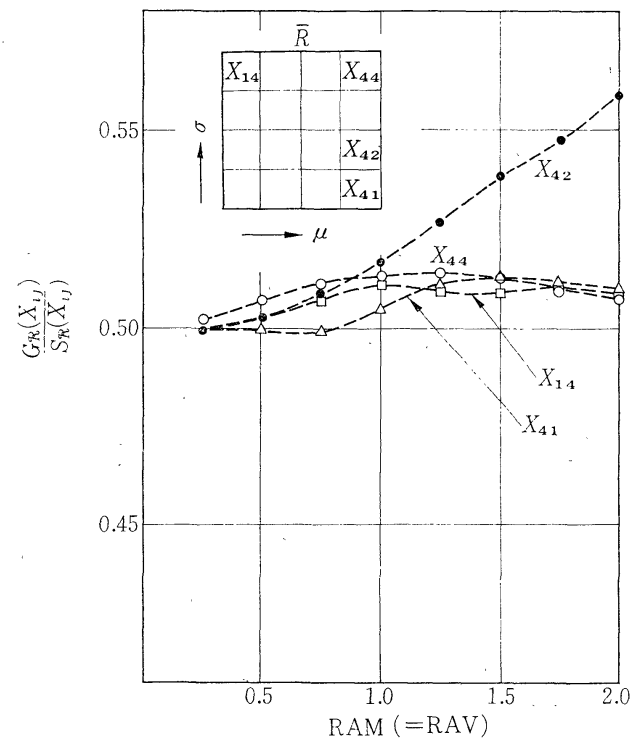

Fig. 3 Relation between information value $G_{R}$ and mean information strength $S_{R}$

RAM，RAV があまり大きくない範囲で（仮定（43） 式は成立していなくとも)，(40) 式は十分に成立して いることがわかる。

$4^{\circ}$ ） 平均情報強度とその成分の特性についての検 討 Fig. 4 は，平均情報強度 $S_{\mathscr{R}}$ の 3 つの成分 Bhattacharyya distance $B$, 相互情報量 $R$, Kullback -Leibler number $I$ の值を， $\bar{R}$ に属するパターンの 各標準偏差值 $\sigma_{i j}$ に対し, 平均值の移動量 $\mu_{i j}$ をパ ラメータとして示したものである. $B$ と $R$ はだいたい 同様の值をとり，両パターンクラスの標準偏差の相違 よりも平均值の差に鋭敏である.この場合, 平均情報 強度 $S_{\mathscr{R}}$ は $B$ あるいは $R$ の約 4 倍である。

また $I$ は $B, R$ に比べると小さな值をとり，ただ平 均値のみに差のある要素 $X_{41}$ に特いてのみかなり大 きな值をとる。これは 2. で述べたように，この要素 に特いては実現值のもつ特幑 $\left(\left|\ln T_{j}^{i}\right|\right)$ の不均一性が 一番顕著であることに起因している。

\section{4. 結言}

ヘイズ形パターソ認識機構の正解率に関連し, 取扱 


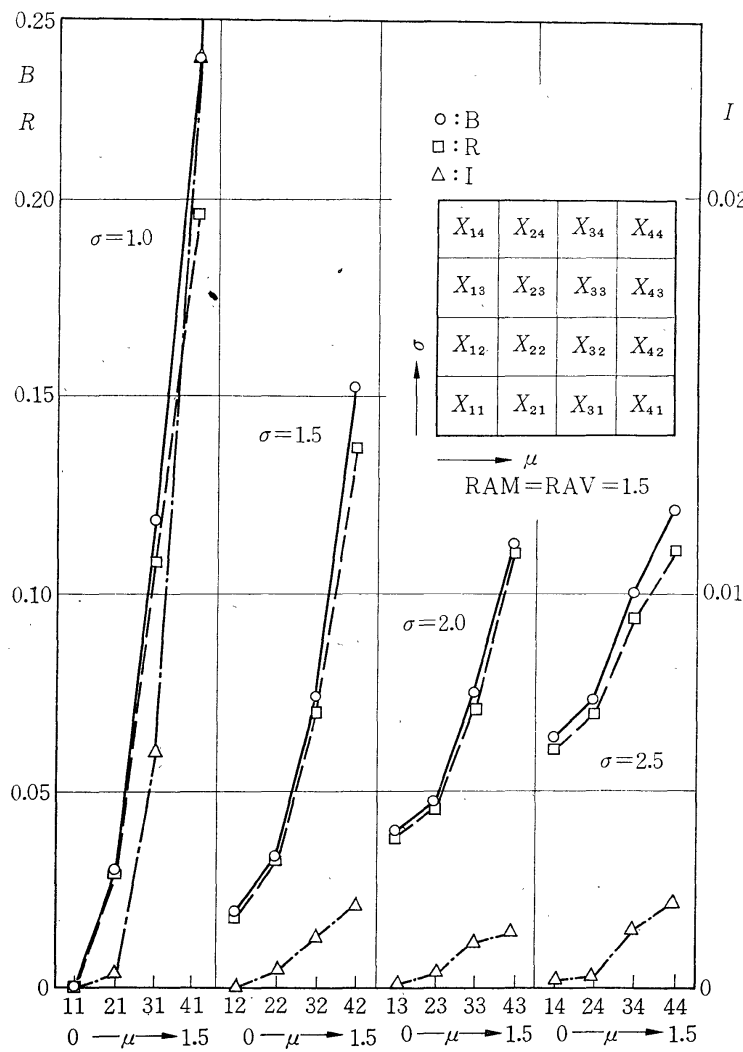

Fig. 4 Quality of Bhattacharyya distance $B$, mutual information $R$ and Kullback-Leibler number $I$

いの簡易な尺度として新しく平均情報強度を定義し， その構造ならびに性質を明らかにした。 すなわち，こ の尺度は情報理論あるいは数理統計学などでよく知ら れた 3 つの尺度に分解される．これら 3 つの成分のパ ターン認識に関してもつ意味から, 平均情報強度の性 質が明らかになった。しかし，第 3 の成分の意味につ いては今後検討する必要がある，また，この尺度とべ
イズ形認識機構の正解率との関係を吟味し, 特に 両パターンクラスの相違の少ない場合には, この 尺度と正解率の間に線形な関係が見い出された。 また，モデルを用いた検討からはより広い範囲で この関係の成立していることがわかった。すなわ ら平均情報強度は, ベイズ形認識機構の構造決定, 特徵抽出問題などに和いて実際的かつ有効な尺度 として用いることがでさる。な特，現在，本尺度 をパターンの最適量子化問題に応用する問題を取 扱っているが，これについては後に発表する予定 である。

\section{参 考 文 献}

1) S. Kullback \& R. A. Leibler: On Information and Sufficiency, Ann. Math. Stat., Vol. 22, 79/86 (1951)

2) S. Kullback: Information Theory and Statistics, John Wiley \& Sons (1952)

3) P.M. Lewis: Approximating Probability Distributions to Reduce Storage Requirement, Inform. \& Contr., Vol. 2, 214/225 (1959)

4) T.Kailath: The Divergence and Bhattacharyya Distance Measures in Signal Selection, IEEE Trans., COM-15-1, 52/60 (1967)

5) T.Y.Young: The Reliability of Linear Feature Extractors, IEEE Trans., C-20-9, 967/971 (1971)

6) A.Caprihan and R.J.P.De Figueiredo: On the Extraction of Pattern Features from Continuous Measurements, IEEE Trans., SSC -6-2, 110/115 (1970)

7) M.E. Hellman and J.Raviv : Probability of Error, Equivocation and the Chernoff Bound, IEEE Trans., IT-16-4, 368/372 (1970)

8) C.E.Shannon and W. Weaver: The Mathematical Theory of Communications, Univ. of Illinois Press (1949)

9）宮沢：情報・決定理論序説，岩波書店（1971）

\section{1. 平均情報強度の 3 成分への分解}

$$
\begin{aligned}
S_{\mathscr{R}}\left(X_{i}\right)= & \sum_{X_{i}=1}^{k}\left\{P\left(X_{i}, R\right) \ln \frac{P\left(X_{i} \mid R\right)}{P\left(X_{i} \mid \bar{R}\right)}+P\left(X_{i}, \bar{R}\right) \ln \frac{P\left(X_{i} \mid \bar{R}\right)}{P\left(X_{i} \mid R\right)}\right\} \\
= & \sum_{X_{i}=1}^{k}\left\{2 P\left(X_{i}, R\right) \ln P\left(X_{i} \mid R\right)-P\left(X_{i}\right) \ln P\left(X_{i} \mid R\right)\right. \\
& \left.+2 P\left(X_{i}, \bar{R}\right) \ln P\left(X_{i} \mid \bar{R}\right)-P\left(X_{i}\right) \ln P\left(X_{i} \mid \bar{R}\right)\right\} \\
= & 2 \sum_{X_{i}=1}^{k}\left\{-P\left(X_{i}\right) \ln P\left(X_{i}\right)+P\left(X_{i}, R\right) \ln P\left(X_{i} \mid R\right)+P\left(X_{i}, \bar{R}\right) \ln P\left(X_{i} \mid \bar{R}\right)\right\} \\
& +\sum_{X_{i}=1}^{k}\left\{2 P\left(X_{i}\right) \ln P\left(X_{i}\right)-P\left(X_{i}\right) \ln P\left(X_{i} \mid R\right)-P\left(X_{i}\right) \ln P\left(X_{i} \mid \bar{R}\right)\right\}
\end{aligned}
$$




$$
\begin{aligned}
= & 2 R\left(X_{i}, \mathscr{R}\right)+2 \sum_{X_{i}=1}^{k} P\left(X_{i}\right) \ln \frac{P\left(X_{i}\right)}{\sqrt{P\left(X_{i} \mid R\right) P\left(X_{i} \mid \bar{R}\right)}} \\
= & 2\left\{R\left(X_{i}, \mathscr{R}\right)-\ln \sum_{X_{i}=1}^{k} \sqrt{P\left(X_{i} \mid R\right) P\left(X_{i} \mid \bar{R}\right)}\right. \\
& \left.+\sum_{X_{i}=1}^{k} P\left(X_{i}\right) \ln \frac{P\left(X_{i}\right)}{\frac{\sqrt{P\left(X_{i} \mid R\right) P\left(X_{i} \mid \bar{R}\right)}}{\sum_{X_{i}=1}^{k} \sqrt{P\left(X_{i} \mid R\right) P\left(X_{i} \mid \bar{R}\right)}}}\right\}
\end{aligned}
$$

2. 正解率近似式の導出 クラス $R$ 亿関する第 1 種過誤の意味での正解率 $P_{R}$ は識別関数 $f(\boldsymbol{X})$ がクラス $R$ のパターンベクトル $\boldsymbol{X}$ に対し，正の值をとる確率で与兄られる．ここに，

$$
f(\boldsymbol{X})=\ln \frac{P(R \mid \boldsymbol{X})}{P(\bar{R} \mid \boldsymbol{X})}=\ln \frac{P(\boldsymbol{X} \mid R)}{P(\boldsymbol{X} \mid \bar{R})}+\ln \frac{P(R)}{P(\bar{R})}
$$

独立性の仮定より, $f$ は独立確率变数 $W_{i}$ の和となる。

$$
f(\boldsymbol{X})=\sum_{i=1}^{n} W_{i}\left(X_{i}\right)+\ln \frac{P(R)}{P(\bar{R})}, \quad W_{i}\left(X_{i}\right)=\ln \frac{P\left(X_{i} \mid R\right)}{P\left(X_{i} \mid \bar{R}\right)}
$$

$n$ が十分大であるから，中心極限定理より $f$ はクラス $R$ において，次の分布に従い，(30) 式が導かれる.

$$
f(\boldsymbol{X}) \sim N\left(\sum_{i=1}^{n} I_{R}\left(X_{i}\right)+\ln \frac{P(R)}{P(\bar{R})}, \sum_{i=1}^{n} V_{R}\left(X_{i}\right)\right)
$$

\section{3. 正解率減少量評価式の導出}

$$
\frac{\beta+\Delta \beta}{\sqrt{\alpha+\Delta \alpha}}-\frac{\beta}{\sqrt{\alpha}} \cong \frac{1}{\sqrt{\alpha}}\left(\Delta \beta-\frac{\beta}{2 \alpha} \Delta \alpha\right)
$$

特よび $d \Phi(x) / d x=\exp \left(-x^{2}\right)$ から，

$$
\Phi\left(\frac{\beta+\Delta \beta}{\sqrt{\alpha+\Delta \alpha}}\right)-\Phi\left(\frac{\beta}{\sqrt{\alpha}}\right) \cong \frac{1}{\sqrt{\alpha}} \exp \left(-\frac{\beta^{2}}{\alpha}\right) \cdot\left(\Delta \beta-\frac{1}{2} \frac{\beta}{\alpha} \Delta \alpha\right)
$$

$\alpha, \beta, \Delta \alpha, \Delta \beta$ として以下の諸量を代入する.

$$
\begin{aligned}
& \alpha=2 \sum_{j \neq i} V_{R}\left(X_{j}\right), \Delta \alpha=2 V_{R}\left(X_{i}\right) \\
& \beta=2 \sum_{j \neq i} I_{R}\left(X_{j}\right), \Delta \beta=I_{R}\left(X_{i}\right)
\end{aligned}
$$

4. 両パターンクラスが類似している場合における $\boldsymbol{I}_{\boldsymbol{R}}, \boldsymbol{V}_{\boldsymbol{R}}$ の值の評価

（43）式の仮定から,

$$
\alpha\left(X_{i}\right) \risingdotseq \frac{P\left(X_{i} \mid \bar{R}\right)-P\left(X_{i} \mid R\right)}{P\left(X_{i} \mid R\right)} \ll 1
$$

ここで $\ln$ そいて Taylor 展開し，(31）式を用いると，

$$
\begin{gathered}
\ln \frac{P\left(X_{i} \mid R\right)}{P\left(X_{i} \mid \bar{R}\right)}=-\alpha\left(X_{i}\right)+\frac{1}{2} \alpha^{2}\left(X_{i}\right)+O\left(\alpha^{3}\right) \\
=\frac{P\left(X_{i} \mid R\right)-P\left(X_{i} \mid \bar{R}\right)}{P\left(X_{i} \mid R\right)}+\frac{1}{2} \frac{\left(P\left(X_{i} \mid R\right)-P\left(X_{i} \mid \bar{R}\right)\right)^{2}}{P^{2}\left(X_{i} \mid R\right)}+O\left(\alpha^{3}\right) \\
I_{R}\left(X_{i}\right)=\sum_{X_{i}=1}^{k} P\left(X_{i} \mid R\right)\left\{\frac{P\left(X_{i} \mid R\right)-P\left(X_{i} \mid \bar{R}\right)}{P\left(X_{i} \mid R\right)}+\frac{1}{2} \frac{\left(P\left(X_{i} \mid R\right)-P\left(X_{i} \mid \bar{R}\right)\right)^{2}}{P^{2}\left(X_{i} \mid R\right)}\right\}+O\left(\alpha^{3}\right) \\
=\sum_{X_{i}=1}^{k}\left\{P\left(X_{i} \mid R\right)-P\left(X_{i} \mid \bar{R}\right)\right\}+\frac{1}{2} \sum_{X_{i}=1}^{k} \frac{\left(P\left(X_{i} \mid R\right)-P\left(X_{i} \mid \bar{R}\right)\right)^{2}}{P\left(X_{i} \mid R\right)}+O\left(\alpha^{3}\right)
\end{gathered}
$$

上式に怙ける第 1 項は明らかに 0 である。 $\alpha$ の 3 次以上の項を省略すると，

$$
I_{R}\left(X_{i}\right) \cong \frac{1}{2} \sum_{X_{i}=1}^{k} \frac{\left(P\left(X_{i} \mid R\right)-P\left(X_{i} \mid \bar{R}\right)\right)^{2}}{P\left(X_{i} \mid R\right)}\left(=O\left(\alpha^{2}\right)\right)
$$

また，同様にして（40）式を用いると，

$$
\begin{aligned}
V_{R}\left(X_{i}\right) & =\sum_{X_{i}=1}^{k} P\left(X_{i} \mid R\right)\left\{\frac{P\left(X_{i} \mid R\right)-P\left(X_{i} \mid \bar{R}\right)}{P\left(X_{i} \mid R\right)}+O\left(\alpha^{2}\right)\right\}^{2}-I_{R}^{2}\left(X_{i}\right) \\
& =\sum_{X_{i}=1}^{k} \frac{\left(P\left(X_{i} \mid R\right)-P\left(X_{i} \mid \bar{R}\right)\right)^{2}}{P\left(X_{i} \mid R\right)}+O\left(\alpha^{3}\right)
\end{aligned}
$$

$\alpha$ の 3 次以上の項を省略することにより，(44）式の関係を得る. 